\title{
P2Y 12 Receptor Antagonist Clopidogrel Attenuates Lung Inflammation Triggered by Silica Particles
}

\begin{abstract}
Patricia Teixeira Santana ${ }^{\dagger}$, Tatiana Luna-Gomes ${ }^{\dagger}$, Marcos Vinicius Rangel-Ferreira, Augusto Shuiti Tamura, Carolyne Lalucha Alves Lima Da Graça, Mariana Nascimento Machado, Walter Araujo Zin, Christina Maeda Takiya, Debora Souza Faffe and Robson Coutinho-Silva*
\end{abstract}

Institute of Biophysics Carlos Chagas Filho, Federal University of Rio de Janeiro, Rio de Janeiro, Brazil

Silicosis is an occupational lung disease caused by inhalation of silica particles. It is characterized by intense lung inflammation, with progressive and irreversible fibrosis, leading to impaired lung function. Purinergic signaling modulates silica-induced lung inflammation and fibrosis through P2X7 receptor. In the present study, we investigate the role of $\mathrm{P}_{2} \mathrm{Y}_{12}$, the G-protein-coupled subfamily prototype of P2 receptor class in silicosis. To that end, BALB/c mice received an intratracheal injection of PBS or silica particles $\left(20 \mathrm{mg}\right.$ ), without or with $\mathrm{P}_{2} \mathrm{Y}_{12}$ receptor blockade by clopidogrel (20 mg/kg body weight by gavage every 48 h) - groups CTRL, SIL, and SIL + Clopi, respectively. After 14 days, lung mechanics were determined by the end-inflation occlusion method. Lung histology was analyzed, and lung parenchyma production of nitric oxide and cytokines (IL-1 $\beta, I L-6, T N F-\alpha$, and TGF- $\beta$ ) were determined. Silica injection reduced animal survival and increased all lung mechanical parameters in relation to CTRL, followed by diffuse lung parenchyma inflammation, increased neutrophil infiltration, collagen deposition and increased pro-inflammatory and profibrogenic cytokine secretion, as well as increased nitrite production. Clopidogrel treatment prevented silica-induced changes in lung function, and significantly reduced lung inflammation, fibrosis, as well as cytokine and nitrite production. These data suggest that inhibition of $\mathrm{P}_{2} \mathrm{Y}_{12}$ signaling improves silica-induced lung inflammation, preventing lung functional changes and mortality. Our results corroborate previous observations of silica-induced lung changes and expand the understanding of purinergic signaling in this process.

Keywords: silica particles, silicosis, purinergic receptors, $\mathrm{P}_{2} \mathrm{Y}_{12}$ receptor, $\mathrm{ADP}$, clopidogrel

\section{INTRODUCTION}

Silicosis is an occupational pneumoconiosis caused by inhalation of silica particles (free crystalline silicon dioxide), which remains a health problem for workers in many industries, including mining and civil construction (Kauppinen et al., 2000; Bhagia, 2012). New forms of exposure to silica particles are added to those classically implied as silica sources, such as dental supply factories using 
quartz fillers (de la Hoz et al., 2004), dental technicians exposed to airborne residuals of silica (Ergün et al., 2014), jewelry workers exposed to silica-containing chalk molds used in casting (Murgia et al., 2007), denim sandblasters (Bakan et al., 2011; Akgun, 2016), and fabricators of artificial-stone worktops (Hoy et al., 2018). Silica particle deposition in lung parenchyma leads to intense inflammatory response, followed by progressive and irreversible lung fibrosis. Depending on the dose, silica may produce acute (accelerated silicosis) or various forms of chronic silicosis (Borges et al., 2002; Castranova et al., 2002; Hnizdo and Vallyathan, 2003; Langley et al., 2004; Rimal et al., 2005). Both high-dose acute and low-dose chronic silica exposures induce granulomatous changes in the lungs. The risk of disease is related to lifetime cumulative exposure and to the amount of inhaled crystalline silica, which, in turn, depends on the concentration and the size of respirable particles, as well as on individual susceptibility (Leung et al., 2012).

Purinergic signaling has been studied during silicosis and various inflammatory contexts, where it contributes to inflammatory exacerbation (Burnstock and Kennedy, 2011; Idzko et al., 2014; Savio et al., 2018). P2 class receptors are activated by extracellular nucleotides, such as ATP and ADP, and are subdivided into two subfamilies: P2X ligand-gated ion channels, and P2Y G-protein-coupled receptors (Burnstock and Kennedy, 2011). We previously demonstrated a significant role for P2X7 receptor as a regulator of silica-induced lung changes. Silica-induced ATP release activates $\mathrm{P} 2 \mathrm{X} 7$ receptor, leading to the production of reactive oxygen species (ROS), inflammasome activation, and IL-1 $\beta$ release (Moncao-Ribeiro et al., 2014). By contrast, the role of $\mathrm{P} 2 \mathrm{Y}$ receptors in silica inflammation is less well understood.

$\mathrm{P}_{2} \mathrm{Y}_{12}$ receptor is mainly, but not exclusively, expressed on platelets. It mediates ADP-induced platelet aggregation, playing a central role in platelet biology (Kim and Kunapuli, 2011). More recently, $\mathrm{P}_{2} \mathrm{Y}_{12}$ expression has been described also in immune cells, such as monocytes (Micklewright et al., 2018), dendritic cells (Ben Addi et al., 2010), and T lymphocytes (Wang et al., 2004). Furthermore, blocking $\mathrm{P}_{2} \mathrm{Y}_{12}$ pathways alters $\mathrm{T}$ cell activation and changes the cell population (Vemulapalli et al., 2019). In the respiratory system, $\mathrm{P}_{2} \mathrm{Y}_{12}$ receptor appears to contribute to inflammatory response, participating in allergic and non-allergic processes (Paruchuri et al., 2009; Shirasaki et al., 2013; Suh et al., 2016), as well as autoimmune disease processes (Domercq et al., 2018). Therefore, to better understand the role of purinergic signaling in silica-induced lung inflammation, we investigated the participation of $\mathrm{P}_{2} \mathrm{Y}_{12}$ receptor in the onset of silicosis.

\section{MATERIALS AND METHODS}

\section{Experimental Group}

This study was approved by the Ethics Committee of the Health Sciences Center, Federal University of Rio de Janeiro (IBCCF164). All animals received humane care according to the Guiding Principles in the Care and Use of Laboratory Animals approved by the Council of the American
Physiological Society. Male Balb/c mice (20-30 g, $n=36$ ) were anesthetized with isoflurane (Isoforine ${ }^{\circledR}$, Cristália, São Paulo, Brazil; 99\% purity) and randomly divided into three groups, intratracheally injected with: phosphate-buffered saline (PBS, $100 \mu \mathrm{L}$ ) (CTRL group) or $20 \mathrm{mg}$ of silica particles (approximately 80\% 1-5 $\mu \mathrm{m}$, Sigma, Chemical Co., St. Louis, MO, United States) without (SIL) or with (SIL + Clopi) clopidogrel (Plavix ${ }^{\circledR}$, Sanofi-Aventis, Paris, France; 99\% purity) treatment $(20 \mathrm{mg} / \mathrm{kg}$ body weight by gavage each $48 \mathrm{~h}$ for 14 days). Animals were analyzed 14 days after PBS or silica administration.

\section{Pulmonary Mechanics}

Pulmonary mechanics were determined as previously described (Moncao-Ribeiro et al., 2014). Briefly, animals were sedated (diazepam $1 \mathrm{mg}$ i.p. Valium ${ }^{\circledR}$, Roche, Basel, Switzerland; 99\% purity), anesthetized (pentobarbital sodium $20 \mathrm{mg} / \mathrm{kg}$ body weight i.p., Nembutal ${ }^{\circledR}$, Merck, Beijing, China; 99\% purity), paralyzed (pancuronium bromide $0.1 \mathrm{mg} / \mathrm{kg}$ body weight i.v. Pancuron ${ }^{\circledR}$, Cristália, São Paulo, Brazil; 99\% purity), and mechanically ventilated (Samay VR15, Universidad de la República, Montevideo, Uruguay) with 100 breaths/min, tidal volume of $0.2 \mathrm{~mL}$, flow of $1 \mathrm{~mL} / \mathrm{s}$, and positive endexpiratory pressure of $2.0 \mathrm{cmH}_{2} \mathrm{O}$. The anterior chest wall was surgically removed, airflow $\left(\mathrm{V}^{\prime}\right)$ was measured using a pneumotachograph $(1.5-\mathrm{mm} \mathrm{ID}$; length $=4.2 \mathrm{~cm}$, distance between side ports $=2.1 \mathrm{~cm}$ ) connected to the tracheal cannula, lung volume was obtained digital integration of the flow signal. The pressure gradient across the pneumotachograph and transpulmonary pressure were determined using Validyne MP-45-2 differential pressure transducers (Engineering Corp., Northridge, CA, United States). Lung airway resistance and stress relaxation/viscoelastic properties [resistive $(\Delta \mathrm{P} 1)$, viscoelastic/inhomogeneous $(\Delta \mathrm{P} 2)$, and total $(\Delta \mathrm{Ptot})$ pressures, respectively], as well as lung elastance and $\Delta \mathrm{E}$, were determined by the end-inflation occlusion method, as previously described (Bates et al., 1985).

\section{Pulmonary Histology and Histomorphometry}

To verify silica-induced pulmonary lesions an additional group of mice subjected to the same experimental protocol described above was used. Fourteen days after PBS or silica injection, the left lungs were collected, fixed with $4 \%$ buffered formaldehyde solution, dehydrated, and embedded in paraffin. Sections (4$\mu \mathrm{m}$ - thick) were cut and stained with hematoxylin-eosin for the description of qualitative alterations in the lung structure. Picrosirius red staining was performed to analyze collagen deposition. For histomorphometry quantifications, a computer-assisted image analysis system comprising a Nikon Eclipse E-800 microscope connected to a computer with a digital camera (Evolution, Media Cybernetics, Bethesda, MD, United States) coupled to Q-Capture 2.95.0 software (Silicon Graphic Inc., Milpitas, CA, United States) was used. High-quality photomicrographs $(2048 \times 1536$ pixel buffer $)$ were captured from non-overlapping lung areas. Data acquisition and analysis were 
done without knowledge of the animal groups in all cases, by the same observer.

Twenty high-quality images of silicotic nodules at $\times 10$ objective lens were analyzed per animal. The surface density of silicotic nodules was calculated as follows: (total nodular area $\times 100)$ /total image area. Neutrophil quantification in lung parenchyma was determined in 16 images/animal at $\times 40$ objective lens (3-5 animals/group). Results were expressed as the total number of neutrophils/histological field. Collagen fiber deposition in lung parenchyma was quantified across 20 random non-coincident fields ( $\times 10$ objective lens). Results were expressed as the percentage of surface density/total image area.

\section{Nitric Oxide and Cytokine Measurements}

The right lungs (from the same animals used for histological study) were macerated for nitric oxide (NO) and cytokine measurements in lung tissue homogenates. NO production was evaluated according to Griess method (Green et al., 1982), and fluorescence was measured at $570 \mathrm{~nm}$ wavelength (SpectraMax M, Molecular Devices, San Jose, CA, United States).

Cytokine concentrations (IL- $1 \beta$, IL-6, TNF- $\alpha$, and TGF- $\beta$ ) were determined by ELISA, with a detection limit of $50 \mathrm{pg} / \mathrm{mL}$ (R\&D Systems, Minneapolis, MN, United States).

\section{Statistical Analysis}

One-way ANOVA, followed by Bonferroni post-test, was used to assess differences among groups. Student's $t$-test for independent samples, Chi-square test or Wilcoxon-MannWhitney test were applied whenever applicable. The level of significance was set at $5 \%$.

\section{RESULTS}

\section{Treatment With P2Y $_{12}$ Receptor Antagonist Reduced Weight Loss and Protected Animals From Death}

Silica exposure induced weight loss along the 14 days after instillation, followed by a 50\% reduction in survival rate. Clopidogrel treatment reduced weight loss (Figure 1A) and significantly improved animal survival (Figure 1B).

\section{P2Y $_{12}$ Receptor Inhibition Led to Minor Changes in Lung Mechanics During Silicosis}

As previously reported (Faffe et al., 2001; Moncao-Ribeiro et al., 2014), silica caused lung functional changes, increasing all lung mechanical parameters in relation to control. Inhibition of the $\mathrm{P}_{2} \mathrm{Y}_{12}$ receptor by clopidogrel broadly improved lung function, including its resistive, elastic, and viscoelastic components (Figure 2).

\section{P2Y $_{12}$ Receptor Inhibition Reduced Cellular Infiltration in Lung Parenchyma}

Silica administration led to intense and diffuse lung parenchyma infiltration of inflammatory cells, such as neutrophils, granulomatous nodular formation, and collagen fibers deposition (Figures 3A,B), as previously described (Faffe et al., 2001; Moncao-Ribeiro et al., 2014). In contrast, clopidogreltreated mice showed preserved areas of lung parenchyma with morphological delimitation of the alveolar septa, significantly fewer neutrophil infiltration, as well as collagen fibers deposition compared with the SIL group (Figures 3C,D).

\section{P2Y12 Receptor Inhibition Reduced Silica-Induced Pro-Inflammatory and Pro-Fibrogenic Cytokine Secretion, as Well as Nitric Oxide Production}

Silica instillation induced pro-inflammatory and pro-fibrogenic cytokine production in lung parenchyma - such as IL-6, IL$1 \beta$, TNF- $\alpha$, and TGF- $\beta$ - as well as increased nitrite production (Figure 4). Conversely, clopidogrel treatment significantly reduced silica-induced cytokine and nitrite secretion (Figure 4).

\section{DISCUSSION}

Purinergic signaling has been implicated in the development of several inflammatory diseases. We have previously demonstrated the role of P2X7 in silicosis (Moncao-Ribeiro et al., 2014; Luna-Gomes et al., 2015), an irreversible and progressive lung fibrotic disease characterized by long-lasting inflammation. The present study expands the understanding of purinergic signaling in silica-induced lung inflammation, evaluating the role of $\mathrm{P}_{2} \mathrm{Y}_{12}$ receptor in a well-established murine model of silicosis. $\mathrm{P}_{2} \mathrm{Y}_{12}$ receptor blockage prevented silica-induced lung inflammatory changes, improving lung function and animal survival. These results demonstrate that $\mathrm{P}_{2} \mathrm{Y}_{12}$ signaling also participates in silicosis onset.

Nucleotides, such as ATP and ADP, are secreted during inflammation and bind to purinergic receptors, stimulating immune system cells in a paracrine and autocrine way (Idzko et al., 2014). Purinergic signaling is mediated by P2X (ATPgated cation channels) and P2Y (G-protein-coupled) receptors (Burnstock, 2007; Shirasaki et al., 2013). P2X7 receptors have been shown important for leukocyte biology (Gu et al., 2000), as well as for silica-induced inflammation through NLRP3 inflammasome activation and IL-1 $\beta$ production (MoncaoRibeiro et al., 2014; Luna-Gomes et al., 2015). On the other hand, $\mathrm{P}_{2} \mathrm{Y}_{12}$ receptors, the prototype of $\mathrm{P} 2 \mathrm{Y}$ subfamily, are important for platelet biology (Buvinic et al., 2002; Guns et al., 2005). Although mainly expressed on platelets, $\mathrm{P}_{2} \mathrm{Y}_{12}$ expression was recently described in other cells of the immune system as well (Wang et al., 2004; Ben Addi et al., 2010; Junger, 2011; Micklewright et al., 2018). Indeed, $\mathrm{P}_{2} \mathrm{Y}_{12}$ receptor blockage influences $\mathrm{T}$ cell activation and cell proliferation. The effect of ADP is specific for CD4 and CD8 T cells, while $\mathrm{P}_{2} \mathrm{Y}_{12}$ antagonism alters these effects, suggesting functional expression of $\mathrm{P}_{2} \mathrm{Y}_{12}$ on T cells (Vemulapalli et al., 2019). We showed previously that silica-induced inflammation increased macrophage, neutrophil, dendritic cell, as well as lymphocyte infiltration $\left(\mathrm{CD} 4^{+}\right.$and $\mathrm{CD}^{+}$) in lung parenchyma (Moncao-Ribeiro et al., 2014). The 

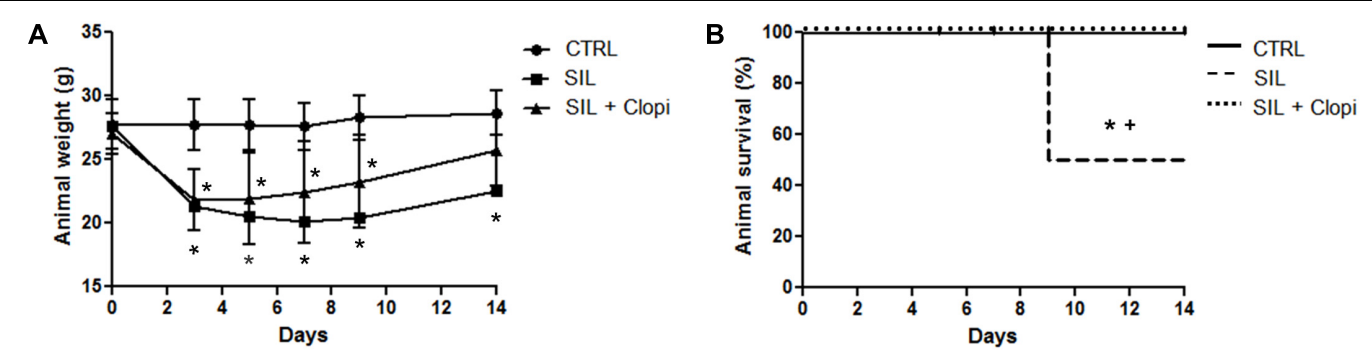

FIGURE 1 | P2Y 12 inhibition reduces silica-induced weight loss and prevents animal death. Body weight (A) and survival (B) were monitored along 14 days after PBS or silica $(20 \mathrm{mg})$ injection without or with clopidogrel treatment $(20 \mathrm{mg} / \mathrm{kg})(\mathrm{CTRL}, \mathrm{SIL}$, and SIL + Clopi groups, respectively). Values are mean \pm SD of $n=5-6$ animals/group. ${ }^{*} p<0.05$ compared with $\mathrm{CTRL} ;{ }^{+} p<0.05$ in relation to SIL + Clopi.

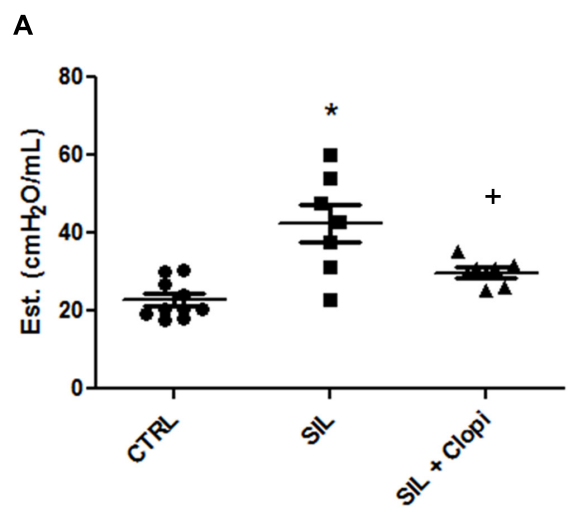

C

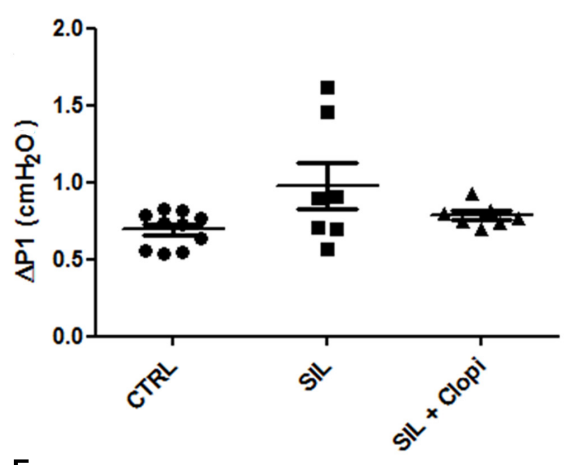

E

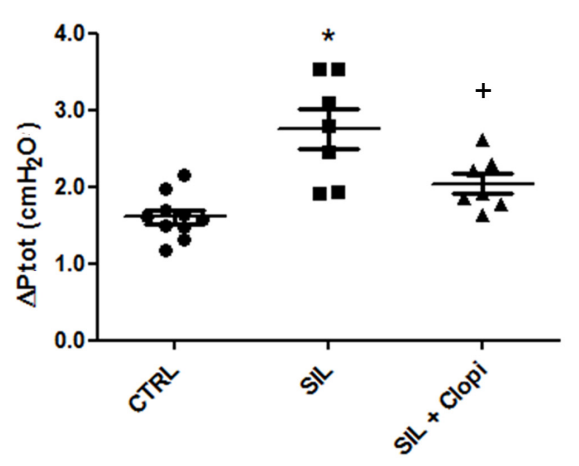

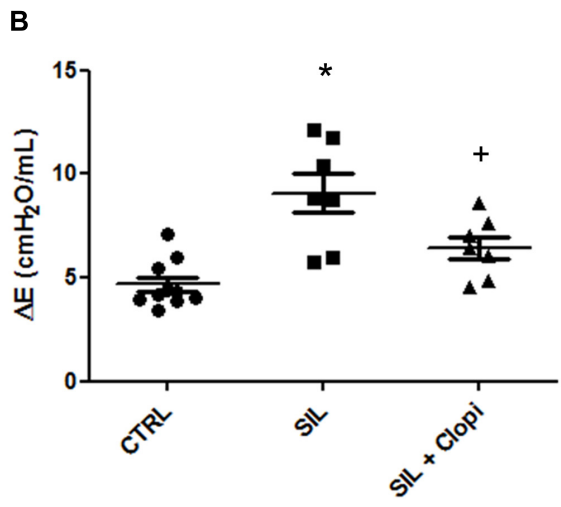

D

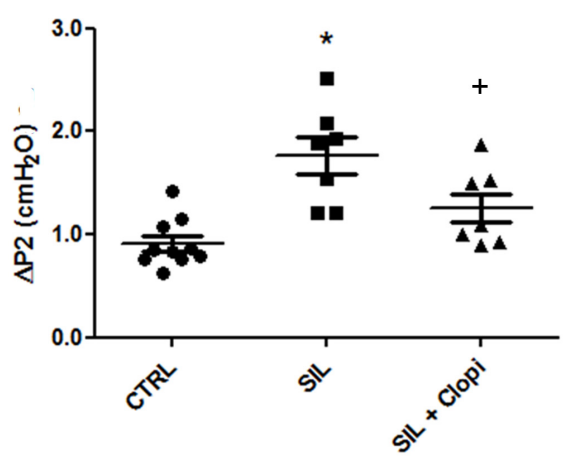

FIGURE 2 | P2 $Y_{12}$ inhibition reduces silica-induced changes in lung mechanics. Lung static elastance (Est, A); viscoelastic component of elastance ( $\triangle E$, B); resistive $(\triangle \mathrm{P} 1, \mathbf{C})$, viscoelastic/inhomogeneous $(\Delta \mathrm{P} 2, \mathbf{D})$, and total $(\Delta \mathrm{Ptot}, \mathbf{E})$ pressures determined 14 days after PBS or silica $(20 \mathrm{mg})$ injection without or with clopidogrel treatment $(20 \mathrm{mg} / \mathrm{kg})(\mathrm{CTRL}, \mathrm{SIL}$, and SIL + Clopi groups, respectively). Values represent mean + SEM of 5-6 animals/group (10 determinations per animal). ${ }^{*} p<0.05$ in relation to control (CTRL); ${ }^{+} p<0.05$ in relation to silica (SIL). 
A

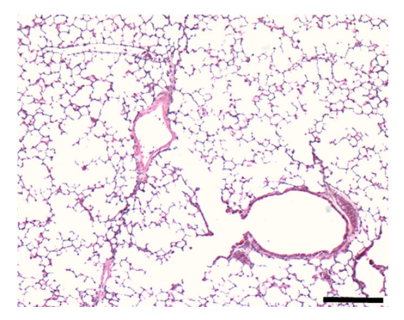

B

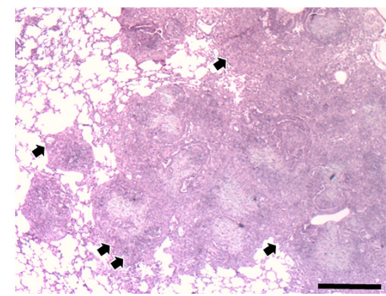

C

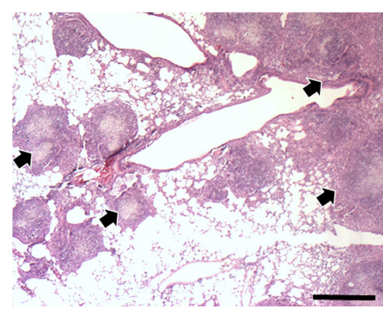

D

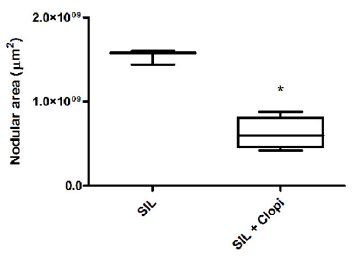

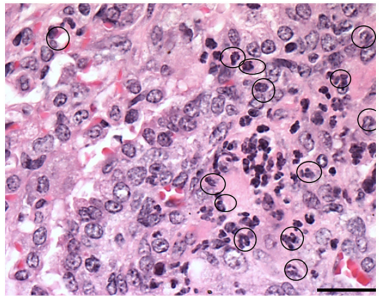
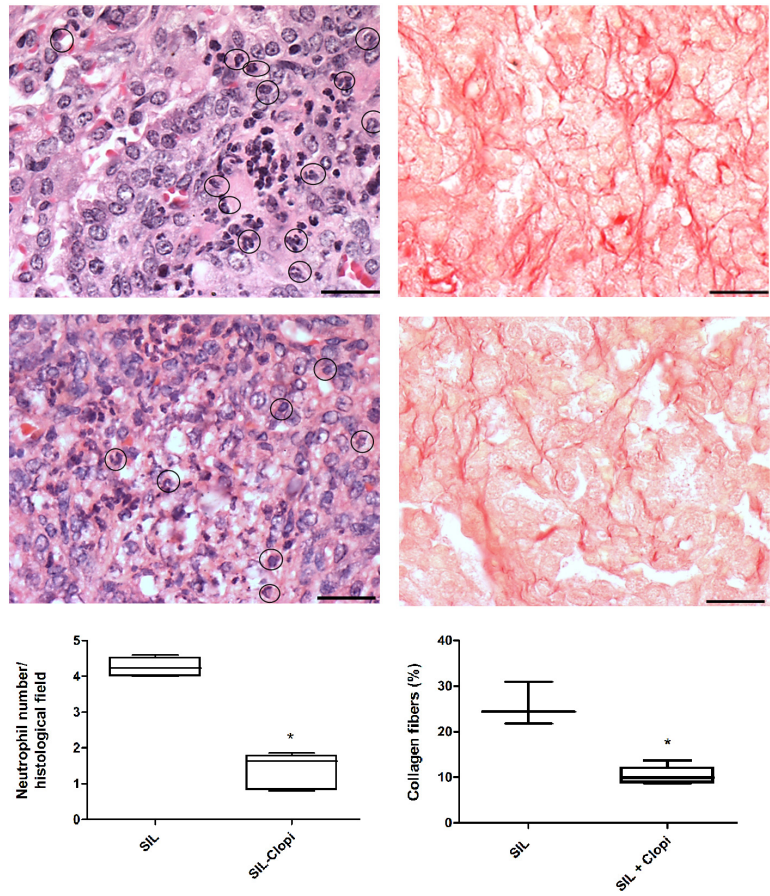

FIGURE 3 | P2 $Y_{12}$ inhibition reduces silicotic lung inflammation and fibrosis. Representative lung parenchyma photomicrographs 14 days after PBS (A) or silica (20 mg) injection without (B) or with (C) clopidogrel treatment (20 mg/kg) (CTRL, SIL, and SIL + Clopi groups, respectively). Hematoxylin-eosin staining (left and central columns) and picrosirius staining (right column). (D) Quantification of nodular area, neutrophil infiltration, and collagen fibers (left, central, and right columns, respectively). Box plots show median values of 3-5 animals/group (16-20 images/animal) with respective minimum to maximum values. ${ }^{*} p<0.05$ in relation to silica (SIL). Arrows show inflammatory infiltrates. Bars: $1000 \mu \mathrm{m}$ (left column), $50 \mu \mathrm{m}$ (central and right columns).

present results now underline important participation of $\mathrm{P}_{2} \mathrm{Y}_{12}$ signaling in inflammatory cell recruitment on the onset of the silicotic process. Our data support also recent evidence of the importance of $\mathrm{P}_{2} \mathrm{Y}_{12}$ in biological functions of other immune cells rather than platelets. Recent data demonstrated a regulatory role for $\mathrm{P}_{2} \mathrm{Y}_{12}$ receptor in regulating neutrophil influx into the lung during sepsis (Liverani et al., 2016). P2Y12 receptor antagonism also reduced inflammation in other inflammation models, including pancreatitis, ischemia-reperfusion, and LPSinduced lung injury (Hackert et al., 2009; Harada et al., 2011; Liu et al., 2011). It is worth note, however, that the $\mathrm{P}_{2} \mathrm{Y}_{12}$ inhibitor clopidogrel - successfully used as antiplatelet medication to prevent thrombus formation in those at high risk - may also have $\mathrm{P}_{2} \mathrm{Y}_{12}$ independent effects during inflammation, and neutrophils are the most likely target (Liverani et al., 2016). Therefore, we cannot exclude an additional direct effect of clopidogrel on reduced inflammation observed after $\mathrm{P}_{2} \mathrm{Y}_{12}$ inhibition.

The immune physiopathology of silicosis involves the activation of inflammatory cells, especially alveolar macrophages.
It has been shown that these cells contribute to increased lung oxidant secretion, as well as other inflammatory mediators, including interleukin $1 \beta$ and tumor necrosis factor-alpha (TNF$\alpha$ ) (Jagirdar et al., 1996). NO is associated with inflammation and damage in asthma and LPS-induced inflammation (Belvisi et al., 1995; Moncao-Ribeiro et al., 2011; Liverani et al., 2014). NO also plays a crucial role in murine silicosis. Silica particle exposure activates macrophages to release NO (Moncao-Ribeiro et al., 2011). In vivo studies showed that mice exposed to silica develop exacerbated lung inflammation, while iNOS-deficient mice are more resistant to silica-induced inflammation (Srivastava et al., 2002). Previous studies showed that silica particle exposure induces TNF- $\alpha$, IL-1 $\beta$, and IL-6 secretion in lung parenchyma in a time-dependent manner (Vanhee et al., 1995; Moncao-Ribeiro et al., 2014). IL-1 $\beta$ is associated with cell recruitment, leading to neutrophil and eosinophil infiltration into lung tissue (Sims and Smith, 2010). In the context of silicosis, the lysis of alveolar macrophage releases cellular components into the extracellular environment, including IL-1 $\beta$, promoting the recruitment of 

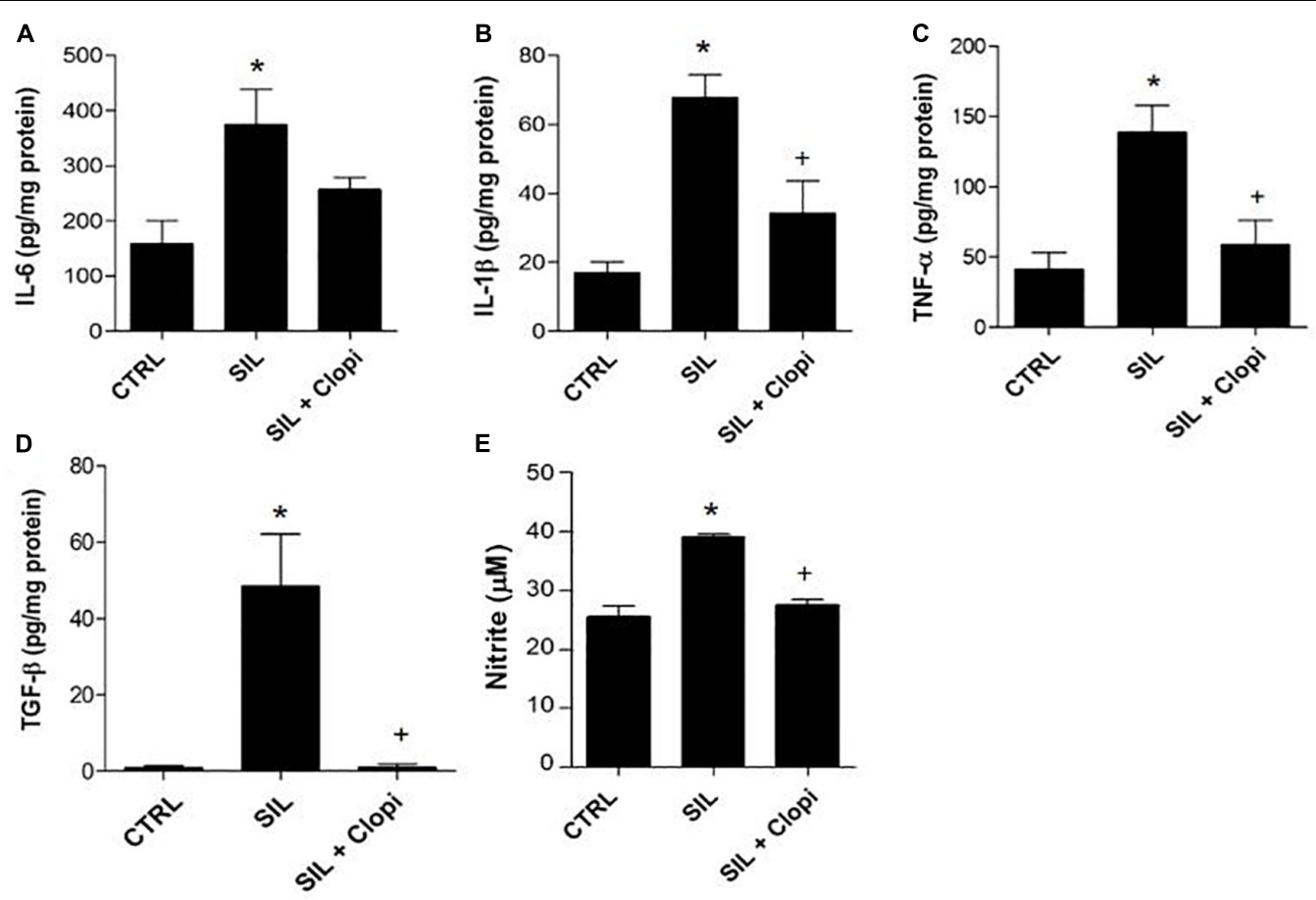

FIGURE 4 | P2Y 12 inhibition reduces silica-induced pro-inflammatory and pro-fibrotic cytokines, as well as nitrite production in lung parenchyma macerates. (A) IL-6, (B) IL-1 $\beta$, and (C) TNF- $\alpha$ pro-inflammatory, and (D) TGF- $\beta$ pro-fibrotic cytokines by ELISA. (E) nitrite production. Values are mean + SEM of 5-6 animals/group determined 14 days after PBS or silica $(20 \mathrm{mg})$ injection without or with clopidogrel treatment $(20 \mathrm{mg} / \mathrm{kg})\left(\mathrm{CTRL}, \mathrm{SIL}\right.$ and SIL + Clopi groups, respectively). ${ }^{\star} p<0.05$ in relation to control (CTRL); ${ }^{+} p<0.05$ in relation to silica (SIL).

inflammatory cells into alveoli and endothelial walls (MoncaoRibeiro et al., 2014). Purinergic signaling participates in IL-1 $\beta$ secretion by macrophages, as well as in NO production through P2X7 activation, as previously demonstrated by our group. On the other hand, $\mathrm{P}_{2} \mathrm{Y}_{12}$ receptor does not participate in cytokine secretion (Vemulapalli et al., 2019), but its blockage significantly reduced NO and the pro-inflammatory mediators IL- 6 and TNF$\alpha$, due to reduced cellular recruitment.

During the silicotic process, injured lung tissue is repopulated with fibroblasts, yielding excessive extracellular matrix deposition and fibrosis, followed by impairment of lung function (Willis and Borok, 2007). In murine models of lung fibrosis, IL$1 \beta$ has been associated with collagen deposition, while IL-1 $\beta$ receptor blockage reduces pulmonary fibrosis caused by silica or bleomycin (Rimal et al., 2005). IL-6 also promotes pulmonary fibrosis after silica exposure, with excessive extracellular matrix proliferation (Le et al., 2014; Tripathi et al., 2010). In addition, TGF- $\beta$ is a main pro-fibrotic mediator in remodeling after tissue injury (Fernandez and Eickelberg, 2012), as well as in the fibrotic process trigged by silica exposure (Jagirdar et al., 1996; Moncao-Ribeiro et al., 2014). TGF- $\beta$ induces extracellular matrix remodeling, collagen production and fibroblast proliferation in the lung parenchyma. Once secreted, TGF- $\beta$ has chemotactic and proliferative effects on fibroblasts (Sime and O'Reilly, 2001). It also stimulates the secretion of various proinflammatory and fibrogenic cytokines, including TNF- $\alpha$, IL-13, and IL-1 $\beta$, thereby increasing and perpetuating the fibrotic response in lung tissue (Fernandez and Eickelberg, 2012). Our results demonstrate that $\mathrm{P}_{2} \mathrm{Y}_{12}$ inhibition significantly reduces TGF- $\beta$ production, thus supporting a role for $\mathrm{P}_{2} \mathrm{Y}_{12}$ signaling in silica-induced fibrosis through TGF- $\beta$ modulation. Silica exposure impairs lung function affecting its elastic, resistive and viscoelastic components. Lung functional changes are secondary to granuloma formation, alveolar collapse, as well as cellular infiltration in the lung parenchyma (Faffe et al., 2001; Moncao-Ribeiro et al., 2014; Cruz et al., 2016). Silica particle inhalation also promotes a fibrogenic response characterized by lung remodeling and replacement of damaged epithelial cells with collagen fiber deposition in the lung parenchyma (Honma et al., 2004; Willis and Borok, 2007). $\mathrm{P}_{2} \mathrm{Y}_{12}$ receptor blockage reduced inflammation and lung remodeling significantly enough to prevent functional changes. Our data corroborate previous observations and expand the understanding of purinergic signaling in silica-induced lung changes. Finally, it is worth note that the animal model of silica-exposure used in the present study does not reproduce chronic silicosis. It does present, however, well-established functional and histological pulmonary changes 14 days after silica administration (Faffe et al., 2001; Borges et al., 2002). Silica-induced chronic lung fibrosis usually results from longlasting inflammation. Therefore, a better understanding of $\mathrm{P}_{2} \mathrm{Y}_{12}$ receptor role in acute inflammation would improve our knowledge about purinergic signaling in silicosis, opening new avenues to modify disease progression. 


\section{CONCLUSION}

In conclusion, our results demonstrate that $\mathrm{P}_{2} \mathrm{Y}_{12}$ receptor is involved in silicosis, probably via its immunomodulatory effects. These findings corroborate and expand previous observations of purinergic signaling participation in silica-induced lung changes. Identification of novel mechanisms involved in disease progression may help in the development of efficient therapies.

\section{DATA AVAILABILITY STATEMENT}

The datasets generated for this study are available on request to the corresponding author.

\section{ETHICS STATEMENT}

The animal study was reviewed and approved by the Ethics Committee of the Health Sciences Center, Federal University of Rio de Janeiro (IBCCF164).

\section{REFERENCES}

Akgun, M. (2016). Denim production and silicosis. Curr. Opin. Pulm. Med. 22, 165-169. doi: 10.1097/MCP.0000000000000249

Bakan, N. D., Özkan, G., Çamsari, G., Gür, A., Bayram, M., Açikmese, B., et al. (2011). Silicosis in denimsandblasters. Chest 148, 647-654.

Bates, J. H., Rossi, A., and Milic-Emili, J. (1985). Analysis of the behavior of the respiratory system with constant inspiratory flow. J. Appl. Physiol. 58, 1840-1848. doi: 10.1152/jappl.1985.58.6.1840

Belvisi, M., Barnes, P. J., Larkin, S., Yacoub, M., Tadjkarimi, S., Williams, T. J., et al. (1995). Nitric oxide synthase activity is elevated in inflammatory lung disease in humans. Eur. J. Pharmacol. 283, 255-258. doi: 10.1016/0014-2999(95)00421-g

Ben Addi, A., Cammarata, D., Conley, P. B., Boeynaems, J. M., and Robaye, B. (2010). Role of the P2Y12 receptor in the modulation of murine dendritic cell function by ADP. J. Immunol. 185, 5900-5906. doi: 10.4049/jimmunol.0901799

Bhagia, L. J. (2012). Non-occupational exposure to silica dust. Indian J. Occup. Environ. Med. 16, 95-100. doi: 10.4103/0019-5278.111744

Borges, V. M., Lopes, M. F., Falcão, H., Leite-Júnior, J. H., Rocco, P. R. M., Davidson, W. F., et al. (2002). Apoptosis underlies immunopathogenic mechanisms in acute silicosis. Am. J. Respir. Cell. Mol. Biol. 27, 78-84. doi: 10.1165/ajrcmb.27.1.4717

Burnstock, G. (2007). Purine and pyrimidine receptors. Cell. Mol. Life Sci. 64, 1471-1483.

Burnstock, G., and Kennedy, C. (2011). P2X receptors in health and disease. Adv. Pharmacol. 61, 333-372. doi: 10.1016/B978-0-12-385526-8.00011-4

Buvinic, S., Briones, R., and Huidobro-Toro, J. P. (2002). P2Y(1) and P2Y(2) receptors are coupled to the NO/cGMP pathway to vasodilate the rat arterial mesenteric bed. Br. J. Pharmacol. 136, 847-856. doi: 10.1038/sj.bjp.0704789

Castranova, V., Porter, D., Millecchia, L., Ma, J. Y., Hubbs, A. F., and Teass, A. (2002). Effect of inhaled crystalline silica in a rat model: time course of pulmonary reactions. Mol. Cell. Biochem. 23, 177-184. doi: 10.1007/978-14615-1087-1_20

Cruz, F. F., Horta, L. F., Maia, L. A., Lopes-Pacheco, M., da Silva, A. B., Morales, M. M., et al. (2016). Dasatinib reduces lung inflammation and fibrosis in acute experimental silicosis. PLoS One 11:e0147005. doi: 10.1371/journal.pone. 0147005

de la Hoz, R. E., Rosenman, K., and Borczuk, A. (2004). Silicosis in dental supply factory workers. Respir. Med. 98, 791-794. doi: 10.1016/j.rmed.2004.01.012

Domercq, M., Zabala, A., and Matute, C. (2018). Purinergic receptors in multiple sclerosis pathogenesis. Brain Res. Bull. 151, 38-45. doi: 10.1016/j.brainresbull. 2018.11.018

\section{AUTHOR CONTRIBUTIONS}

PS, TL-G, and RC-S drafted the manuscript. MR-F, TL-G, and PS conducted and analyzed the data from all experiments. $\mathrm{AT}$ and $\mathrm{CD}$ conducted the cytokine measurement experiments. DF, WZ, CT, and RC-S contributed to the conception and design of the study, and revised the draft. All authors contributed to the manuscript revision, and approved the submitted version.

\section{FUNDING}

This work was supported by grants from the Conselho Nacional de Desenvolvimento Científico e Tecnológico (CNPq, Brazil 300531/2012-5, 311362/2014-1, 448152/2014-2, 302702/2017-2, and 401372/2016-2) and Fundação de Amparo à Pesquisa do Estado do Rio de Janeiro (FAPERJ, Brazil E-26/010.002985/2014, E-26/201.450/2014, E-26/203.027/2015, E-26/202.785/2017, and E-26/202.774/2018).

Ergün, D., Ergün, R., Ozdemir, C., Ozis, T. N., Yilmaz, H., and Akkurt, I. (2014). Pneumoconiosis and respiratory problems in dental laboratory technicians: analysis of 893 dental technicians. Int. J. Occup. Med. Environ. Health. 27, 785-796. doi: 10.2478/s13382-014-0301-9

Faffe, D. S., Silva, G. H., Kurtz, P. M., Negri, E. M., Capelozzi, V. L., Rocco, P. R., et al. (2001). Lung tissue mechanics and extracellular matrix composition in a murine model of silicosis. J. Appl. Physiol. (1985) 90, 1400-1406. doi: 10.1152/jappl.2001.90.4.1400

Fernandez, I. E., and Eickelberg, O. (2012). The impact of TGF-beta on lung fibrosis: from targeting to biomarkers. Proc. Am. Thorac. Soc. 9, 111-116. doi: 10.1513/pats.201203-023AW

Green, L. C., Wagner, D. A., Glogowski, J., Skipper, P. L., Wishnok, J. S., and Tannenbaum, S. R. (1982). Analysis of nitrate, nitrite, and [15N]nitrate in biological fluids. Anal. Biochem. 126, 131-138. doi: 10.1016/0003-2697(82) 90118-x

Gu, B. J., Zhang, W. Y., Bendall, L. J., Chessell, I. P., Buell, G. N., and Wiley, J. S. (2000). Expression of $\mathrm{P} 2 \mathrm{X}(7)$ purinoceptors on human lymphocytes and monocytes: evidence for nonfunctional P2X(7) receptors. Am. J. Phys. Cell. Physiol. 279, C1189-C1197.

Guns, P. J., Korda, A., Crauwels, H. M., Van, A. T., Robaye, B., Boeynaems, J. M., et al. (2005). Pharmacological characterization of nucleotide P2Y receptors on endothelial cells of the mouse aorta. Br. J. Pharmacol. 146, 288-295. doi: 10.1038/sj.bjp.0706326

Hackert, T., Sperber, R., Hartwig, W., Fritz, S., Schneider, L., Gebhard, M. M., et al. (2009). P-selectin inhibition reduces severity of acute experimental pacreatitis. Pancreatology 9, 369-374. doi: 10.1159/000212098

Harada, K., Matsumoto, Y., and Umemura, K. (2011). Adenosine diphosphate receptor $\mathrm{P} 2 \mathrm{Y} 12$-mediated migration of host smooth muscle-like cells and leukocytes in the development of transplant arteriosclerosis. Transplantation 92, 148-154. doi: 10.1097/TP.0b013e318221d407

Hnizdo, E., and Vallyathan, V. (2003). Chronic obstructive pulmonary disease due to occupational exposure to silica dust: a review of epidemiological and pathological evidence. Occup. Environ. Med. 60, 237-243. doi: 10.1136/oem.60. 4.237

Honma, K., Abraham, J. L., Chiyotani, K., De, V. P., Dumortier, P., Gibbs, A. R., et al. (2004). Proposed criteria for mixed-dust pneumoconiosis: definition, descriptions, and guidelines for pathologic diagnosis and clinical correlation. Hum. Pathol. 35, 1515-1523. doi: 10.1016/j.humpath.2004. 09.008

Hoy, R. F., Baird, T., Hammerschlag, G., Hart, D., Johnson, A. R., King, P., et al. (2018). Artificial stone-associated silicosis: a rapidly emerging occupational 
lung disease. Occup. Environ. Med. 75, 3-5. doi: 10.1136/oemed-2017104428

Idzko, M., Ferrari, D., and Eltzschig, H. K. (2014). Nucleotide signalling during inflammation. Nature 509, 310-317. doi: 10.1038/nature13085

Jagirdar, J., Begin, R., Dufresne, A., Goswami, S., Lee, T. C., and Rom, W. N. (1996). Transforming growth factor-beta (TGF-beta) in silicosis. Am. J. Respir. Crit. Care Med. 154, 1076-1081.

Junger, W. G. (2011). Immune cell regulation by autocrine purinergic signalling. Nat. Rev. Immunol. 11, 201-212. doi: 10.1038/nri2938

Kauppinen, T., Toikkanen, J., Pedersen, D., Young, R., Ahrens, W., Boffetta, P., et al. (2000). Occupational exposure to carcinogens in the European Union. Occup. Environ. Med. 57, 10-18. doi: 10.1136/oem.57.1.10

Kim, S., and Kunapuli, S. P. (2011). P2Y12 receptor in platelet activation. Platelets 22, 56-60. doi: 10.3109/09537104.2010.497231

Langley, R. J., Kalra, R., Mishra, N. C., Hahn, F. F., Razani-Boroujerdi, S., Singh, S. P., et al. (2004). A biphasic response to silica: I. Immunostimulation is restricted to the early stage of silicosis in Lewis rats. Am. J. Respir. Cell Mol. Biol. 30, 823-829. doi: 10.1165/rcmb.2003-0284oc

Le, T. T., Karmouty-Quintana, H., Melicoff, E., Le, T. T., Weng, T., Chen, N. Y., et al. (2014). Blockade of IL-6 Trans signaling attenuates pulmonary fibrosis. J. Immunol. 193, 3755-3768. doi: 10.4049/jimmunol.1302470

Leung, C. C., Yu, I. T., and Chen, W. (2012). Silicosis. Lancet 379, 2008-2018. doi: 10.1016/S0140-6736(12)60235-9

Liu, Y., Gao, X. M., Fang, L., Jennings, N. L., Su, Y., Q, X., et al. (2011). Novel role of platelets in mediating inflammatory responses and ventricular rupture or remodeling following myocardial infarction. Arterioscler. Thromb. Vasc. Biol. 31, 834-841. doi: 10.1161/ATVBAHA.110.220467

Liverani, E., Rico, M. C., Tsygankov, A. Y., Kilpatrick, L. E., and Kunapuli, S. P. (2016). P2Y12 receptor modulates sepsis-induced inflammation. Arterioscler. Thromb. Vasc. Biol. 36, 961-971. doi: 10.1161/ATVBAHA.116.307401

Liverani, E., Rico, M. C., Yaratha, L., Tsygankov, A. Y., Kilpatrick, L. E., and Kunapuli, S. P. (2014). LPS-induced systemic inflammation is more severe in P2Y12 null mice. J. Leukoc. Biol. 95, 313-323. doi: 10.1189/jlb.1012518

Luna-Gomes, T., Santana, P. T., and Coutinho-Silva, R. (2015). Silica-induced inflammasome activation in macrophages: role of ATP and P2X7 receptor. Immunobiology 220, 1101-1106. doi: 10.1016/j.imbio.2015.05.004

Micklewright, J. J., Layhadi, J. A., and Fountain, S. J. (2018). P2Y12 receptor modulation of ADP-evoked intracellular $\mathrm{Ca}(2+)$ signalling in THP-1 human monocytic cells. Br. J. Pharmacol. 175, 2483-2491. doi: 10.1111/bph.14218

Moncao-Ribeiro, L. C., Cagido, V. R., Lima-Murad, G., Santana, P. T., Riva, D. R., Borojevic, R., et al. (2011). Lipopolysaccharide-induced lung injury: role of P2X7 receptor. Respir. Physiol. Neurobiol. 179, 314-325. doi: 10.1016/j.resp. 2011.09.015

Moncao-Ribeiro, L. C., Faffe, D. S., Santana, P. T., Vieira, F. S., da Graca, C. L., Marques-da-Silva, C., et al. (2014). P2X7 receptor modulates inflammatory and functional pulmonary changes induced by silica. PLoS One 9:e110185. doi: 10.1371/journal.pone.0110185

Murgia, N., Muzi, G., Dell'Omo, M., Sallese, D., Ciccotosto, C., Rossi, M., et al. (2007). An old threat in a new setting: high prevalence of silicosis among jewelry workers. Am. J. Ind. Med. 50, 577-583. doi: 10.1002/ajim.20490

Paruchuri, S., Tashimo, H., Feng, C., Maekawa, A., Xing, W., Jiang, Y., et al. (2009). Leukotriene E4-induced pulmonary inflammation is mediated by the P2Y12 receptor. J. Exp. Med. 206, 2543-2555. doi: 10.1084/jem.20091240
Rimal, B., Greenberg, A. K., and Rom, W. N. (2005). Basic pathogenetic mechanisms in silicosis: current understanding. Curr. Opin. Pulm. Med. 11, 169-173. doi: 10.1097/01.mcp.0000152998.113 35.24

Savio, L. E. B., de Andrade, M. P., da Silva, C. G., and Coutinho-Silva, R. (2018). The P2X7 receptor in inflammatory diseases: angel or demon? Front. Pharmacol. 9:52. doi: 10.3389/fphar.2018.00052

Shirasaki, H., Kanaizumi, E., Seki, N., Kikuchi, M., and Himi, T. (2013). Expression and localization of purinergic P2Y(12) receptor in human nasal mucosa. Allergol. Int. 62, 239-244. doi: 10.2332/allergolint.12-OA0496

Sime, P. J., and O'Reilly, K. M. (2001). Fibrosis of the lung and other tissues: new concepts in pathogenesis and treatment. Clin. Immunol. 99, 308-319. doi: 10.1006/clim.2001.5008

Sims, J. E., and Smith, D. E. (2010). The IL-1 family: regulators of immunity. Nat. Rev. Immunol. 10, 89-102. doi: 10.1038/nri2691

Srivastava, K. D., Rom, W. N., Jagirdar, J., Yie, T. A., Gordon, T., and Tchou-Wong, K. M. (2002). Crucial role of interleukin-1beta and nitric oxide synthase in silica-induced inflammation and apoptosis in mice. Am. J. Respir. Crit. Care Med. 165, 527-533. doi: 10.1164/ajrccm.165.4.2106009

Suh, D. H., Trinh, H. K., Liu, J. N., Pham, L. D., Park, S. M., Park, H. S., et al. (2016). P2Y12 antagonist attenuates eosinophilic inflammation and airway hyperresponsiveness in a mouse model of asthma. J. Cell. Mol. Med. 20, 333-341. doi: $10.1111 / \mathrm{jcmm} .12727$

Tripathi, S. S., Mishra, V., Shukla, M., Verma, M., Chaudhury, B. P., Kumar, P., et al. (2010). IL-6 receptor-mediated lung Th2 cytokine networking in silicainduced pulmonary fibrosis. Arch. Toxicol. 84, 947-955. doi: 10.1007/s00204010-0559-z

Vanhee, D., Gosset, P., Boitelle, A., Wallaert, B., and Tonnel, A. B. (1995). Cytokines and cytokine network in silicosis and coal workers' pneumoconiosis. Eur. Respir. J. 8, 834-842.

Vemulapalli, H., Albayati, S., Patwa, V. C., Tilley, D. G., Tsygankov, A. Y., and Liverati, E. (2019). ADP exerts P2Y12-dependent and P2Y12-independent effects on primary human $\mathrm{T}$ cell responses to stimulation. J. Cell Commun. Signal. [Epub ahead of print].

Wang, L., Jacobsen, S. E., Bengtsson, A., and Erlinge, D. (2004). P2 receptor mRNA expression profiles in human lymphocytes, monocytes and CD34+ stem and progenitor cells. BMC Immunol. 5:16. doi: 10.1186/1471-2172-5-16

Willis, B. C., and Borok, Z. (2007). TGF-beta-induced EMT: mechanisms and implications for fibrotic lung disease. Am. J. Physiol. Lung Cell. Mol. Physiol. 293, L525-L534.

Conflict of Interest: The authors declare that the research was conducted in the absence of any commercial or financial relationships that could be construed as a potential conflict of interest.

Copyright (c) 2020 Santana, Luna-Gomes, Rangel-Ferreira, Tamura, Da Graça, Machado, Zin, Takiya, Faffe and Coutinho-Silva. This is an open-access article distributed under the terms of the Creative Commons Attribution License (CC BY). The use, distribution or reproduction in other forums is permitted, provided the original author(s) and the copyright owner(s) are credited and that the original publication in this journal is cited, in accordance with accepted academic practice. No use, distribution or reproduction is permitted which does not comply with these terms. 